\title{
La ciudad que quisiéramos después de COVID-19
}

\author{
Alfonso Xavier Iracheta Cenecorta ${ }^{1}$ \\ Recibido: 20-06-2020 | en su versión final: 30-06-2020
}

Ante la pandemia coyuntural y la crisis sistémica global "Una premisa esencial es entender que la ecología NO es un capítulo de la economía, sino que ésta lo es de la ecología

(Enrique Dussel, 2020)

Resumen

La pandemia de COVID-19 ha impactado profundamente las economías e incrementado la desigualdad y la pobreza. Los cambios pueden ser tan profundos que difícilmente las cosas serán igual que antes en la región latinoamericana y en sus ciudades. La magnitud del fenómeno ha sido muy diferente en los países con mayor presencia de la enfermedad. Reconocemos que esta emergencia es apenas la "punta del iceberg" de la crisis sistémica del capitalismo y que sus impactos en las ciudades han sido profundos. Una breve revisión del contexto histórico reciente del desarrollo desigual e insustentable en el subcontinente muestra que ha generado ciudades con problemas tan profundos en lo social, económico, espacial y ambiental, que representan un caldo de cultivo para la pandemia, para las amenazas (cambio climático, desigualdad socioespacial) y para otras crisis sanitarias que seguramente vendrán en el futuro. Ante este panorama, proponemos que "otra ciudad es posible" si reconocemos que se necesitan cambios de fondo más allá de lo ordinario: salir del capitalismo fósil, reducir el consumo de energía, recuperar los ecosistemas, transformar las ciudades. Requerimos una "matriz territorial" diferente que reconozca a las ciudades como espacios para el desarrollo y no destinos fatales; que ponga por delante el "derecho a la ciudad" y el "derecho de la naturaleza"; que sean bien gobernadas con la participación de los ciudadanos. Recuperemos las buenas experiencias: teletrabajo con derechos, reconstruir a fondo las políticas de vivienda, de expansión urbana y de movilidad. ¿Es posible imaginar una respuesta tan enérgica como ante COVID-19 frente al cambio climático y la desigualdad socioespacial?

Palabras clave: COVID-19; desarrollo urbano; América Latina

Citación

Iracheta, A. (2020). La ciudad que quisiéramos después de COVID-19. ACE: Architecture, City and Environment, 15(43), 9512. DOI: http://dx.doi.org/10.5821/ace.15.43.9512

\begin{abstract}
${ }^{1}$ Doctor en Estudios Regionales. Investigador de El Colegio Mexiquense, México. Director General de Centro EURE SC; Consultor de la Fundación Friedrich Ebert, Onu-h, BID. Fue miembro del Consejo Asesor de ONUHabitat; Asesor Principal del Índice de Prosperidad Urbana para México de ONU-Habitat; Investigador Nacional SNI. Ha publicado o co-editado 35 libros y coordinado 198 estudios e Investigaciones y Planes y Programas de Desarrollo Territorial. (ORCID: 0000-0001-7511-3198, Scopus Author: 56916149400). Correos de contacto: axicorta@gmail.com, axic@cmq.edu.mx
\end{abstract}

ACE, 15 (4:3) CC BY-ND 3.0 ES | UPC Barcelona, España | La ciudad que quisiéramos después de COVID-19. 1 DOI: http://dx.doi.org/10.5821/ace.15.43.9512 


\section{The City We Would Like After COVID-19}

Abstract

COVID-19 pandemic has deeply affected the economy and deepening inequality and poverty. Changes are going to be so deep that it is difficult to imagine that things will be as they were before the disease in Latin American countries and their cities. The magnitude of the phenomenon has been different among Latin American countries. We recognize that this crisis is the "top of the iceberg" of capitalism endemic crisis and that its impacts on cities have been profound. A brief account of recent historical urban context of Latin American unequal and unsustainable development process shows that it has delivered cities with social, economic, spatial and environmental deep problems which represent a breeding ground for COVID-19, as well as for climate change and social inequality's threats and for new pandemics to come. Before this panorama we propose that "other city is possible", if it is recognized that deep changes have to be carried out beyond the ordinary ones: health of fossil capitalism; reduce energy consumption; recover ecosystems; transform cities. A different "territorial matrix" that recognizes cities as spaces for development not as fatal destinies is needed; able to put ahead the "right to the city" and the "right of nature" and that cities should be well governed with social participation. We have to recover recent good practices: work at home with labor rights, thoroughly rebuild housing, urban expansion and mobility policies. Is it possible to imagine a response as energetic as before COVID-19 against climate change and socio-spatial inequality?

Keywords: COVID-19; urban development; Latin America

\section{Introducción}

Probablemente el término que mejor podría expresar la etapa de la historia humana en la que irrumpió la pandemia del COVID-19 es incertidumbre. Incertidumbre del presente por el desconocimiento inicial sobre sus impactos, por la falta de certezas en los diagnósticos y sobre los tratamientos de la enfermedad, por la ausencia de certeza temporal ya que no se tiene claridad sobre su permanencia, si terminará o no y sobre los riesgos de rebrotes. Incertidumbre en el futuro, porque lo que se tenía como cierto, como lógico, como cotidiano, hasta la toma de conciencia global de la pandemia, parece desvanecerse. Y todo ello está ocurriendo en tiempos cada vez más reducidos que no han permitido hacer un alto en el camino para reflexionar sobre los grandes impactos y transformaciones que estamos enfrentando, ya que antes requerían décadas y ahora parecen comprimir el tiempo a unos cuantos meses. En el ámbito latinoamericano estas incertidumbres se agudizan por ser la región del globo más afectada por la pandemia al escribir este texto (junio 2020) y porque sus capacidades y sus instituciones no garantizan certezas en el presente y tampoco en el futuro inmediato.

Estas incertidumbres no implican necesariamente la imposibilidad de solución o cuando menos de atenuación de la crisis. Lo que sí evidencian, es que la pandemia ha creado nuevos problemas y está teniendo un efecto exponencial y visibilizador de los viejos problemas estructurales, haciéndolos más vigentes y urgentes; y esto implica que debemos asumir nuestra responsabilidad para repensar y proyectar otras estrategias que nos lleven a transformaciones de fondo: del mercado capitalista, de la política, del consumo, del respeto a la naturaleza y de las ciudades y la vida urbana. 
De ello trata este texto. En la primera parte referimos algunos datos puntuales sobre la magnitud de los impactos de la pandemia en América Latina enfatizando su origen y magnificación en algunos países. En la segunda hacemos referencia, desde la historia reciente, al contexto urbano del subcontinente, que nos lleva a asumir que la crisis de salud es apenas una muestra de la profunda crisis socioespacial que enfrentan las ciudades de la región. En la tercera sección analizamos la ciudad latinoamericana resultante de esta crisis, destacando algunos problemas que han sido caldo de cultivo para la diseminación de la pandemia y lo seguirán siendo para las amenazas que se ciernen sobre la región -y a nivel global- como el cambio de clima y otras pandemias que ya se asumen como previsibles. Concluimos el texto con algunas ideas que están en los debates sobre cómo imaginar el futuro urbano post-pandemia, ya que ésta nos ha ofrecido la posibilidad de hacer profundos replanteamientos y propuestas que vayan más allá de lo común y lo ordinario o que nos regresen al statu quo anterior, para luchar por una transformación que ponga al frente el derecho a la ciudad y también el derecho de la naturaleza.

\section{COVID-19: la magnitud del problema}

La pandemia de CORONAVIRUS se originó en una ciudad, se diseminó por la movilidad física de las personas -especialmente por viajes aéreos- y extendió su contagio en los espacios urbanos principalmente. Las razones del aceleramiento del contagio han sido la cercanía y la interacción física entre personas, lo que facilita la trasmisión del virus.

Si algo caracteriza la vida urbana es el contacto cotidiano y constante entre las personas; desde el saludo cortés con las manos o con besos en las mejillas (uno, dos y hasta tres, según diferentes culturas), hasta el contacto cercano entre parejas, padres-hijos y amistades, entre otros. Prácticamente todas las actividades económicas y sociales de las personas en las ciudades implican este tipo de contactos.

De acuerdo con la información diariamente difundida por los medios de comunicación y especialmente por las redes sociales, además del contacto físico directo, la diseminación del virus ocurre también por el contacto físico indirecto que se da por la permanencia temporal del virus en diversos tipos de superficies; de ahí que tocar objetos y/o superficies que han sido contaminadas por personas infectadas puede trasmitir el virus.

Si a estas condiciones se agrega el concepto de densidad de población en las ciudades, en su versión general como promedio en toda el área urbana o en sus barrios, o más específica en aglomeraciones de personas que se transportan masivamente en sistemas de metro o similares, que acuden a abastecerse en mercados o centros comerciales o que participan de espectáculos masivos artísticos, culturales, deportivos- y eventos - religiosos, políticos, sociales-, los riesgos de contagio se multiplican sin límite ni control, provocando la expansión de la enfermedad y la de sus consecuencias.

Los datos oficiales evidencian un crecimiento exponencial del contagio y un crecimiento alto de fallecimientos atribuibles a la pandemia en varios países, destacando Brasil, Perú, Chile, México, Ecuador y Colombia a partir del número total de personas contagiadas por COVID-19 y del número de fallecimientos por cada 100 mil habitantes (con excepción de Colombia) (Tabla 1 y Figura 1). Si bien la letalidad en relación con el número de contagios confirmados es relativamente baja -con excepción de México y Ecuador-, se entiende que la preocupación gubernamental y social no se refiere sólo a ésta, sino a las insuficiencias de los sistemas de salud para atender el gran número de contagiados en un periodo sumamente corto, por la falta de personal capacitado, instalaciones, equipos, utensilios y medicamentos que la atención de esta enfermedad exige, lo cual significa que muchas vidas pudieran salvarse si se contara con las condiciones sanitarias adecuadas.

ACE, 15 (4:3) CC BY-ND 3.0 ES | UPC Barcelona, España | La ciudad que quisiéramos después de COVID-19.

DOI: http://dx.doi.org/10.5821/ace.15.43.9512 
La gran mayoría de los casos confirmados de contagio y de fallecimientos han ocurrido en las áreas urbanas, destacando las grandes ciudades -Sâo Paulo, Guayaquil, CDMX-, y en ellas se han evidenciado las limitaciones de las políticas sanitarias y urbanas ya que ni la localización, ni la accesibilidad a las instalaciones hospitalarias son adecuadas desde la óptica de una estrategia espacial acorde al tamaño de población y a su localización. Por ello, los asentamientos humanos de bajo ingreso e informalidad en la tenencia de la tierra ubicados en las periferias urbanas resultan ser los grandes perdedores por la ausencia de servicios de salud en su entorno y por la limitada accesibilidad a los existentes.

Tabla 1. Número de casos confirmados de COVID-19 en ALC por país (27 de junio, 2020)

\begin{tabular}{|l|c|c|c|}
\hline \multicolumn{1}{|c|}{ País } & Casos & Fallecimientos & $\%$ \\
\hline Brasil & $1,274,974$ & 55,961 & 0.04 \\
\hline Perú & 272,364 & 8,939 & 0.03 \\
\hline Chile & 263,360 & 5,068 & 0.02 \\
\hline México & 208,392 & 25,779 & 0.12 \\
\hline Ecuador & 53,856 & 4,406 & 0.08 \\
\hline Colombia & 80,811 & 2,786 & 0.03 \\
\hline Argentina & 55,343 & 1,184 & 0.02 \\
\hline República Dominicana & 29,764 & 712 & 0.02 \\
\hline Panamá & 29,905 & 575 & 1.90 \\
\hline Bolivia & 29,423 & 934 & 0.03 \\
\hline Guatemala & 15,828 & 672 & 0.04 \\
\hline Honduras & 15,994 & 471 & 0.03 \\
\hline El Salvador & 5,517 & 133 & 0.02 \\
\hline Haití & 5,722 & 98 & 0.02 \\
\hline Cuba & 2,325 & 85 & 0.04 \\
\hline Venezuela & 4,779 & 41 & 0.01 \\
\hline Costa Rica & 2,836 & 12 & 0.00 \\
\hline
\end{tabular}

Fuente: John Hopkins University (2020).

Figura 1. COVID-19, fallecimientos por cada 100 mil habitantes en América Latina (27 de junio, 2020)

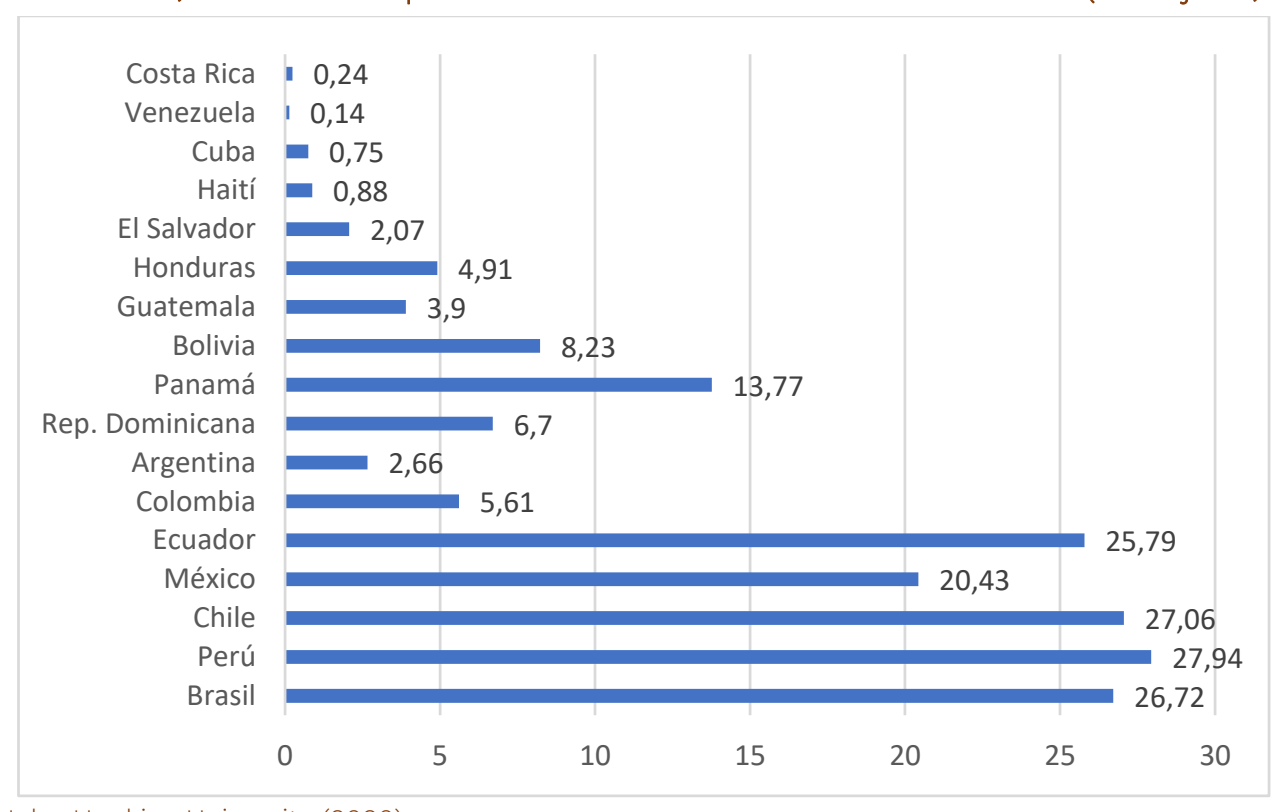

Fuente: John Hopkins University (2020).

Por el número de fallecimientos por cada 100 mil habitantes destacan seis países: Ecuador, Brasil, Perú, Chile, México y Panamá que, con excepción de Argentina y Colombia, son países con alta movilidad de población a nivel internacional asociada a sus economías y con alta concentración de población urbana en grandes urbes.

ACE, 15 (4:3) CC BY-ND 3.0 ES | UPC Barcelona, España | La ciudad que quisiéramos después de COVID-19. 
Las figuras 2 y 3 muestran la evolución y crecimiento de la pandemia en la región latinoamericana y del Caribe y en los países con mayor concentración de casos y de fallecimientos desde su inicio en febrero de 2020 hasta el 27 de junio del mismo año. La multiplicación de casos y su concentración en apenas cinco países es muy evidente.

Figura 2. Evolución de COVID-19 América Latina y El Caribe (marzo a junio 27, 2020)

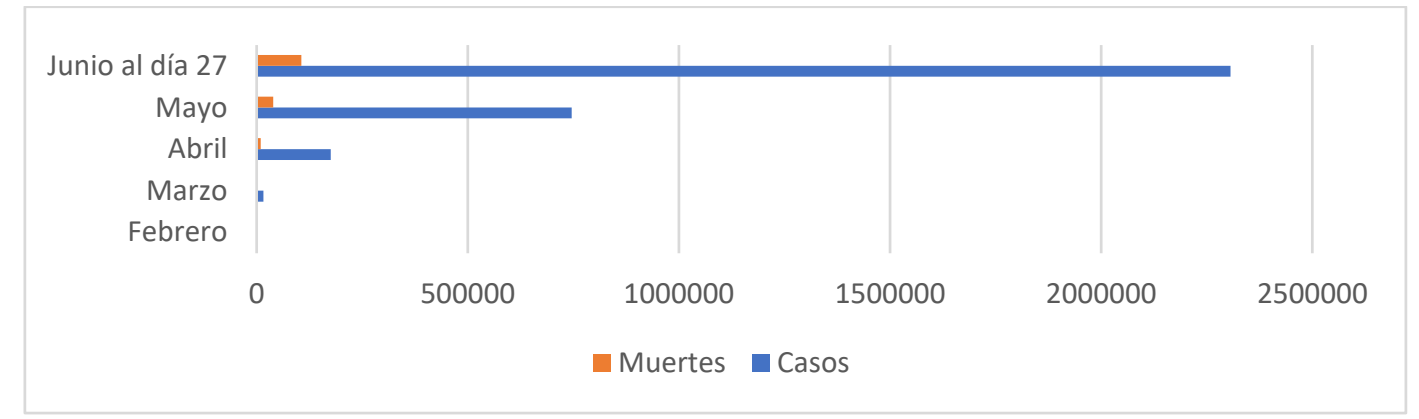

Fuente: Elaboración propia con datos de la OMS (2020). Notas: Casos: corresponde al número de casos acumulados al último día de cada mes. Muertes: corresponde al número de muertes acumuladas al último día de cada mes. Esta gráfica muestra la suma del número de casos y muertes acumuladas por mes de todos los países de América Latina y el Caribe (45 países), con corte al 27 de junio de 2020.

Figura 3. COVID-19, países con más casos confirmados (febrero a junio 27, 2020)

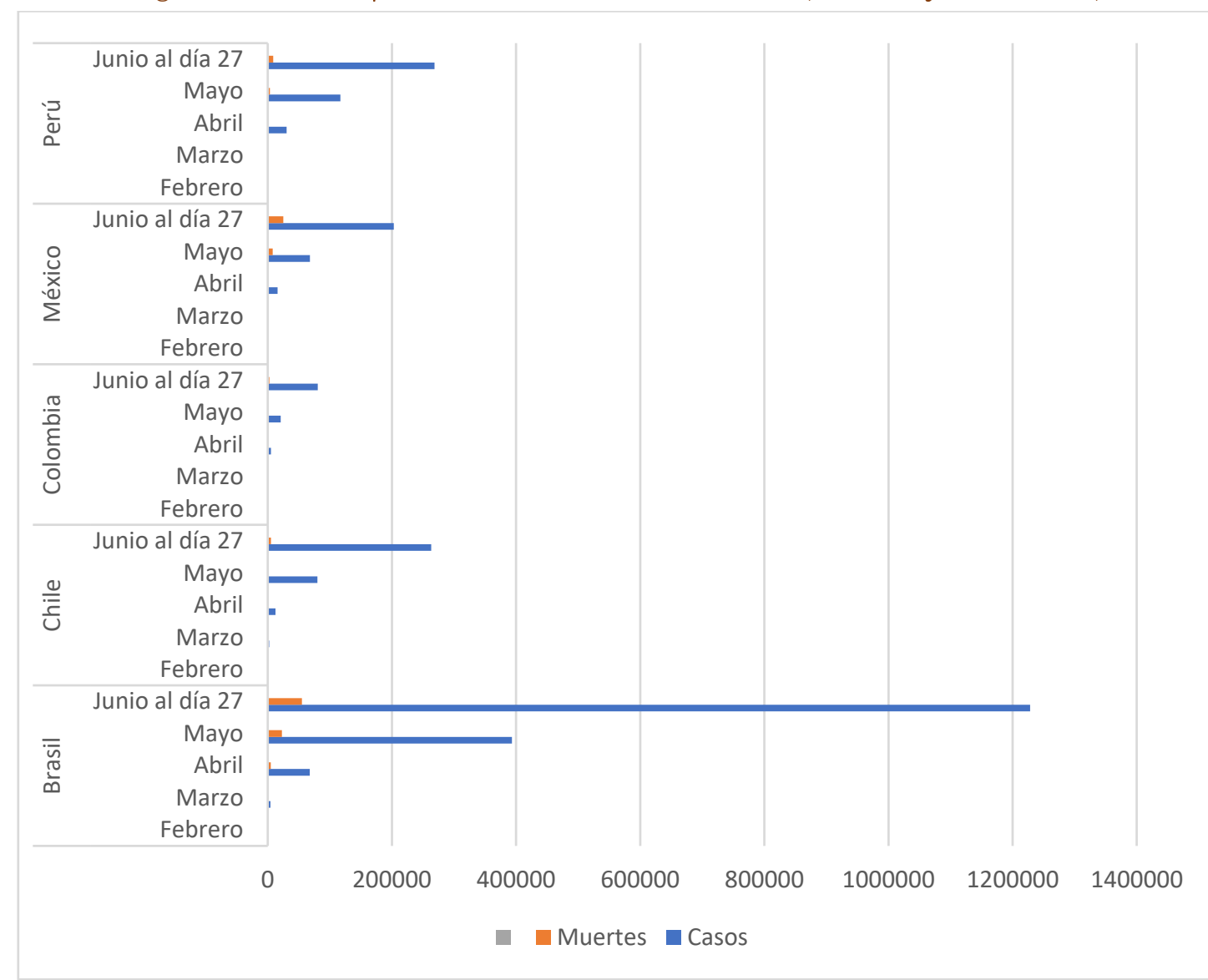

Fuente: Elaboración propia con datos de la OMS (2020). Notas: Casos: corresponde al número de casos acumulados al último día de cada mes. Muertes: corresponde al número de muertes acumuladas al último día de cada mes.

ACE, 15 (43) CC BY-ND 3.0 ES | UPC Barcelona, España | La ciudad que quisiéramos después de COVID-19. 5 DOI: http://dx.doi.org/10.5821/ace.15.43.9512 
De acuerdo con las proyecciones del Massachusetts Institute of Technology (MIT) en el corto plazo destaca el crecimiento de casos de contagio en Brasil, Chile y Colombia, mientras que en México se mantendría el número de contagios sin crecimiento apreciable, pero se incrementaría de manera relevante el número de fallecimientos (Figura 4).

Figura 4. COVID-19, proyección de casos activos y fallecimientos en Norte América y Sudamérica (junio 30 a agosto 15, 2020)

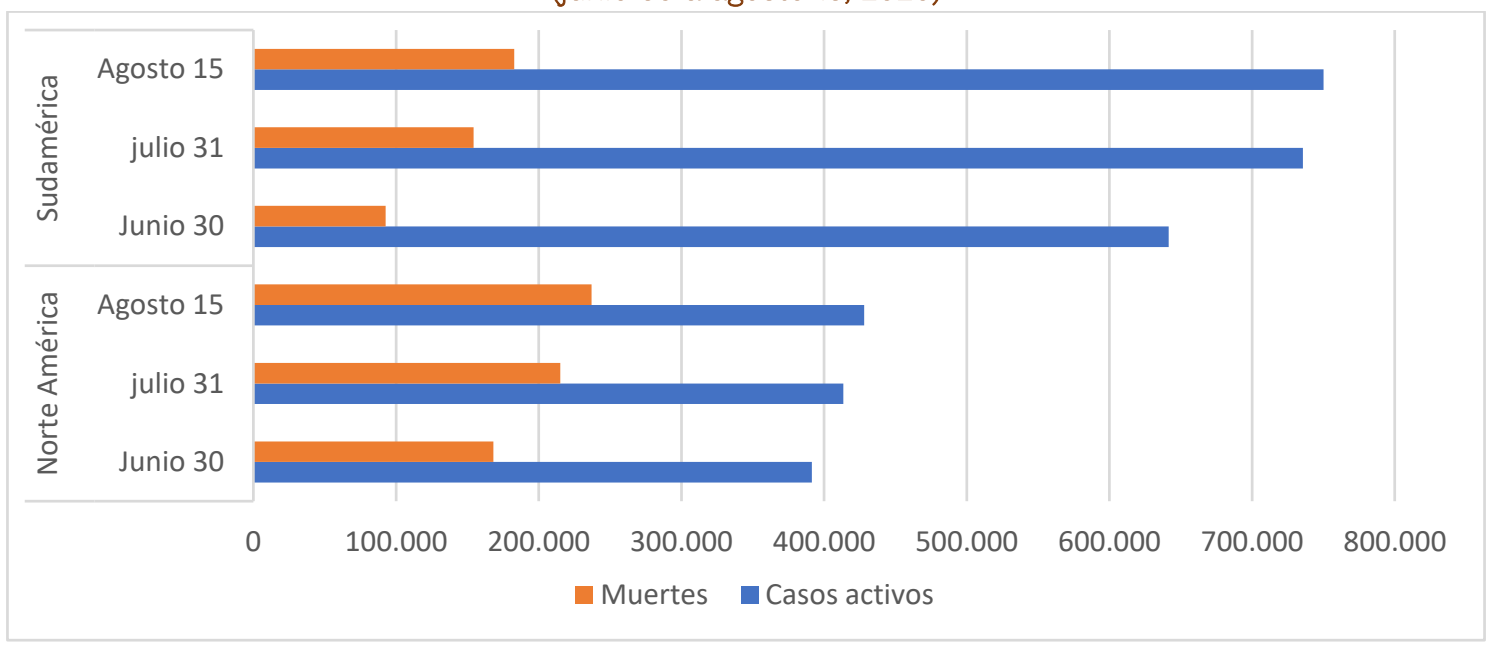

Fuente: Elaboración propia con datos de MIT, COVID Analytics (2020). Notas: Casos activos: un caso activo de COVID-19 es una persona que ha sido detectada con COVID y que todavía no se ha recuperado o fallecido, corresponde entonces al número de casos activos proyectados para cada fecha. Muertes: corresponden al número total de muertes acumuladas, desde el primer fallecimiento, hasta la fecha marcada.

El conjunto de gráficas sobre la evolución y proyección de la enfermedad muestra grandes diferencias de política entre los países latinoamericanos aquí considerados. Mientras unos reducen sensiblemente los fallecimientos en otros se aceleran, ocurriendo algo similar con los casos positivos (Figuras 3 y 5).

La incertidumbre en los datos y estas diferencias de política hacen necesario que los expertos en epidemiología, salud pública y ciencias sociales analicen en profundidad cada política nacional y particularmente sus contextos sobre morbilidad y sobre las condiciones sanitarias de sus ciudades y sus barrios, a fin de entender un poco mejor las causas de estos comportamientos tan diferenciados.

Sólo como ejemplo destacamos el caso de México: con aproximadamente 32 millones de hipertensos de una población de 127 millones de habitantes; con 25 millones de fumadores; segundo lugar mundial en obesidad (el primero es EUA); con cerca de 12 millones de diabéticos y uno de los mayores consumidores de bebidas azucaradas y "comida chatarra" en el mundo, organizaciones sociales (\#CambiemosHábitos y \#PorUnMexicoSano) se preguntan ¿de quién es la culpa de tantos fallecimientos? La información desplegada hasta ahora, sugiere que la gravedad y agudizamiento de la pandemia está asociada a estos factores -entre otros- de comorbilidad.

Igualmente, después de varios meses de sufrir la pandemia y de analizarse día a día las políticas y medidas sanitarias en los países por expertos y medios de comunicación, destacan varios factores a considerar: la laxitud vs el rigor y obligatoriedad de las medidas generalmente asumidas (quédate en casa; mantén la sana distacia; utiliza el cubreboca; lávate las manos regularmente; sanitiza las superficies y objetos) han sido claramente diferenciadas en los ámbitos nacionales y urbanos y han tenido resultados diferentes en la expansión del virus y en la mortalidad (ej. Argentina confinando obligatoriamente a la población; Brasil dejando pasar y hacer sin mayores controles; México recomendando las medidas sin obligación para la población). 
Otras preguntas surgen desde la perspectiva urbana que los estudios futuros deberían tratar de responder: ¿Qué significa para una ciudad carecer de suficientes espacios e instalaciones para la atención de la salud de toda la población? ¿Qué le significa tener ubicados sus hospitales sin criterios de localización asociados con la prevención y atención a la salud? ¿Qué significa que en muchas ciudades existan periferias con asentamientos precarios, alejados de los centros urbanos y carentes de buena parte de los servicios básicos sanitarios (agua potable y drenaje) y de los equipamientos de salud? Ante el contagio, ¿qué posibilidades reales tienen los más pobres de acceder con prontitud y a muy bajo costo a un servicio médico y hospitalario; qué posibilidades tienen de mantener sus empleos y su ingreso? ¿Qué significaría la existencia de sistemas comunitarios de prevención y atención a la salud en los barrios densos de las ciudades?

La mayoría de las posibles respuestas a estas preguntas tendería a confirmar que a diferencia de otros equipamientos sociales generalmente ubicados en el nivel de barrio, incluyendo muchos de bajo ingreso, como la educación básica, el abasto alimentario e inclusive las instalaciones para los cultos religiosos, los equipamientos de salud de primera atención son mucho más escasos, porque tiende a prevalecer la idea de concentrar en grandes instalaciones hospitalarias desde la primera atención hasta cierto nivel de especialidades. Ante esto, cualquier enfermedad pandémica u otra amenaza de orden social afectarán proporcionalmente más a quienes menos tienen, evidenciando la injusticia y desigualdad que rige en los países latinoamericanos y en buena parte de sus ciudades.

Figura 5. COVID-19, proyección de casos activos y fallecimientos en países con más casos confirmados $^{1}$ (junio 30 a agosto 15,2020 )

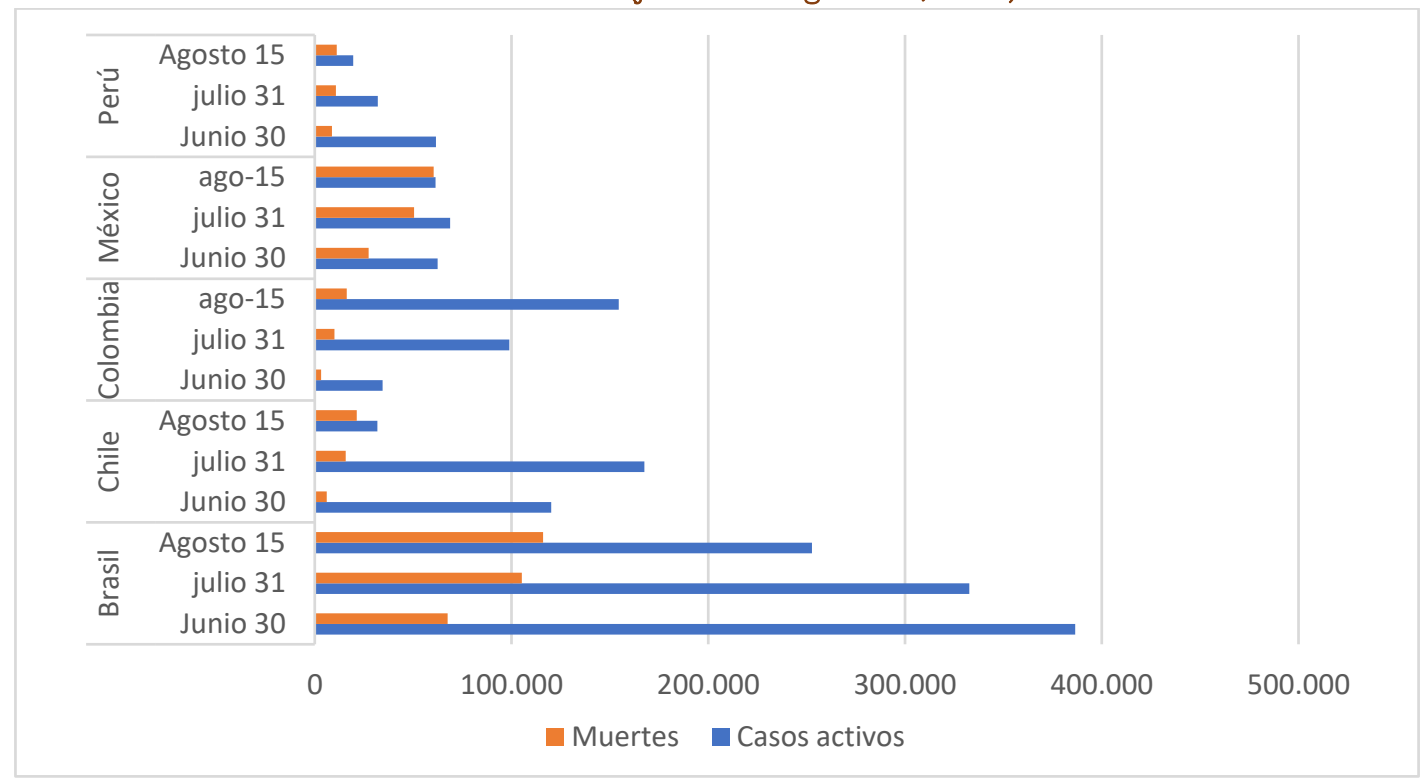

Fuente: Elaboración propia con datos de MIT, COVID Analytics (2020). Notas: Casos activos: Un caso activo de COVID-19 es una persona que ha sido detectada con COVID y que todavía no se ha recuperado o fallecido, corresponde entonces al número de casos activos proyectados para cada fecha. Muertes: Corresponden al número total de muertes acumuladas, desde el primer fallecimiento hasta la fecha marcada.

${ }^{1}$ El modelo DELPHI (Differential Equations Leads to Predictions of Hospitalizations) es un modelo de comportamiento basado en el modelo SEIR (modelaje matemático de epidemias, el cual calcula el número de contagiados, fallecidos y pacientes recuperados), pero con algunas adiciones para obtener resultados más aproximados a la realidad. En particular,g toma en cuenta dos efectos importantes:

1. La subdetección: en cualquier pandemia, muchos casos pasan desapercibidos debido a muchos factores (falta de registro, incapacidad para realizar pruebas, confusiones con otra enfermedad, etc.). Es un factor importante que si no se cuenta adecuadamente puede resultar en una subestimación del alcance real y la propagación de la epidemia.

2. Respuesta gubernamental: no existe una epidemia en un mundo en el que se permita su propagación completamente libre. A medida que se propaga la epidemia, los gobiernos comienzan a responder mediante la promulgación de políticas diseñadas para limitar la propagación del virus, y diseñamos explícitamente un marco para tener en cuenta dichas políticas en el modelo (Lingzhi Li, 2020: 1).

ACE, 15 (4:3) CC BY-ND 3.0 ES | UPC Barcelona, España | La ciudad que quisiéramos después de COVID-19. 


\section{El contexto urbano latinoamericano antes de COVID-19}

El mundo y América Latina están llegando a límites por el modo y magnitud de producir y de consumir. La destrucción y pérdida de los valores ambientales pone en peligro la vida de los seres vivos, incluyendo a los humanos. La externalización de los costos ambientales, aunado a la inmensa desigualdad social y espacial y a la concentración de la riqueza "...nos muestran los errores sistémicos del capitalismo fósil que pervive en el siglo XXI y las deficiencias de la economía global” (Friedrich Ebert Stiftung, 2019, p. 9).

La emergencia sanitaria es apenas la "punta del iceberg" de la crisis sistémica del capitalismo. La globalización ha acrecentado los riesgos y América Latina enfrenta una convergencia de varias crisis: de los sistemas de salud, de instituciones generalmente débiles, de economías basadas fundamentalmente en la explotación extractivista e insustentable de los recursos naturales, de riesgos en las libertades personales, de limitaciones en la economía de los cuidados y de estructuras socioeconómicas profundamente desiguales. Y para enfrentar estas crisis, los rangos de maniobra son muy limitados en lo fiscal y monetario, en el financiamiento de la salud, en las capacidades de los Estados para redistribuir la riqueza, para reducir las brechas educativas y digitales, para reducir las emisiones de gases de efecto invernadero (GEI) y para ordenar las ciudades y los territorios.

Estos problemas y limitaciones han moldeado a las sociedades latinoamericanas que han tenido una profunda transformación desde la irrupción del Modelo Neoliberal (de 1980 a la fecha). Como argumenta De Mattos (2010, p. 701-702), se recomendó a los países “...la aplicación de políticas de disciplina fiscal, tasas de cambio 'competitivas', liberalización del comercio, promoción de la inversión extranjera, privatizaciones, etc., que constituyen los componentes básicos del fenómeno conocido como neoliberalismo".

Con estos cambios, los objetivos de la gestión del desarrollo en general y del desarrollo de la ciudades en particular se desplazaron de la cuestión social a las diferencias en materia de producción y sus capacidades, y a diferencias de competitividad de los sectores de la economía y de los territorios, con lo cual las políticas territoriales y urbanas se orientaron a favorecer la creación de recursos y nueva riqueza y no a la afectación y redistribución de las riquezas existentes (De Mattos, 2010, p. 703704).

Desde entonces, la economía de las ciudades ha sufrido una reconversión. Destaca la priorización de la competitividad económica, asociada a la atracción de capitales, la desregulación y las facilidades de todo tipo para las inversiones, otorgando los gobiernos al empresariado privado el papel de actor social crucial del desarrollo y partiendo del supuesto de que los capitales son condición necesaria para el crecimiento económico y un requisito para mejorar los niveles de empleo e ingreso, para atraer nuevos talentos y para desarrollar las infraestructuras y equipamientos sociales en las ciudades, así como las nuevas tecnologías y la innovación.

David Harvey (1989, p. 7, en De Mattos, 2010, p. 704-705) ha denominado este cambio en la gestión y planificación de los territorios como "empresarialista", porque se fundamenta en un partenariado público-privado que realiza actividades empresariales y con fuerte dominio de lo mercantil por encima de lo público al tener una conceptualización y ejecución especulativa, y porque su foco de atención es la economía política local y no la del territorio.

Esta interpretación permite explicar los cambios en las fuentes de empleo al interior de las ciudades, que transitan del industrial a espacios para el capital inmobiliario, constructor y financiero, impulsado por un sector terciario (comercio, servicios, turismo, otros) que desplazó a la industria. Igualmente, la transformación en la concepción de la gestión urbana de la época keynesiana a la neoliberal, que ha

ACE, 15 (4:3) CC BY-ND 3.0 ES | UPC Barcelona, España | La ciudad que quisiéramos después de COVID-19. 
significado un cambio en los objetivos de la política pública de la búsqueda por disminuir las desigualdades socioespaciales y avanzar en la cohesión del tejido social, a la maximización del crecimiento económico, la generación de empleo y facilitar/tolerar la especulación mercantil con las funciones de las ciudades.

Es la época de la abdicación gubernamental de las decisiones relevantes de localización de los usos del suelo y del relativo abandono público de la coordinación y la conducción del proceso de urbanización. Es, igualmente, la época de las grandes políticas nacionales de apoyo a los mercados para acelerar la concentración de la población y de las actividades económicas en las ciudades, en especial en las grandes metrópolis, ofreciendo las condiciones para la generación de economías de aglomeración y de escala, y las requeridas por el capital financiero e inmobiliario para concentrar sus inversiones en las grandes ciudades, dando paso al fenómeno de la "financiarización".

Es también el momento, especialmente con el inicio del nuevo siglo, de la explosión de la oferta de vivienda social auspiciada por los gobiernos nacionales, como por ejemplo, la Política habitacional en Chile ("los Sin Techo", Sugranyes et al., 2014), "Mia Casa, Mia Vida" en Brasil, "Política Nacional Habitacional" en México, entre otras; de la invasión definitiva del automóvil en las ciudades hasta llegar a la saturación; de la generalización del precarismo habitacional periférico (la "urbanización de la pobreza” de ONU-Hábitat) y del reconocimiento del papel urbano en el cambio climático y en el deterioro ambiental (UN-Habitat, 2011).

Una característica de estos procesos, desde la óptica de la salud a nivel social, es el generalizado desinterés -desde el Estado y desde los mercados- por elaborar estrategias de desarrollo urbano y/o habitacional que incluyeran la prevención y atención de la salud, al igual que la desatención a otras funciones urbanas como la cultural o deportiva, por ser poco atractivas a las fracciones de capital que han detentado en buena parte la expansión de las ciudades a través de sus proyectos inmobiliarios y la construcción de infraestructuras.

Con el nuevo siglo, se profundiza la crisis del capitalismo neoliberal que incluye también a las ciudades de América Latina, y se revalúan sus perspectivas de desarrollo y sus riesgos -viejos y nuevos-. Ante este panorama, el mundo enfrenta un cambio que se augura DE ÉPOCA, cuando menos por dos razones: La primera, el cambio climático y otras amenazas como las pandemias (COVID-19 en 2020 y las que se esperan en el futuro) y la segunda, el hartazgo social por las desigualdades crecientes en las naciones y su hiperconcentración en las ciudades.

Ante esto, emergen nuevos enfoques, por iniciativas locales o por gestiones externas, como la Nueva Agenda Urbana promovida por ONU-Hábitat. Es también el surgimiento en Latinoamérica de “...el llamado momento post-neoliberal que caracteriza a la oleada de gobiernos progresistas que fueron mayoría sobre todo en Sudamérica entre 2005 y 2014" (Calix, 2017, p. 1).

Desde la perspectiva de De Mattos (2010, p. 713), ante las condiciones que se imponen en la geografía mundial emergen diversas posiciones que se sustentan “...en la convicción de que es posible fortalecer la cohesión social y la armonía interna [de los territorios] para superar cualquier conflictividad interna, en torno a [los] intereses generales del lugar. Al ubicarse en esta postura, esta 'nueva ortodoxia' presta escasa atención a los condicionamientos y a la acción social que se derivan del contexto estructural capitalista, lo que significa, en especial, que no aparecen como relevantes las diferencias de poder entre los distintos actores que forman la correspondiente sociedad regional o local".

Es decir, se asume que una adecuada gobernanza urbana, de abajo hacia arriba, sería factible para manejar los procesos, capacidades y las condiciones de desarrollo de las poblaciones locales, lo que deja sin la adecuada consideración a la dependencia de las sociedades locales hacia el capital y el

ACE, 15 (4:3) CC BY-ND 3.0 ES | UPC Barcelona, España | La ciudad que quisiéramos después de COVID-19. 
papel privilegiado que tienen sus propietarios en cada territorio para determinar las decisiones fundamentales sobre el desarrollo de las regiones y las ciudades.

Otros enfoques para enfrentar los problemas territoriales actuales reconocen que los procesos socioespaciales no están circunscritos a condiciones de armonía y consenso, sino que operan en condiciones de contradicción y asimetría, y de conflicto por el espacio y por los recursos de toda naturaleza. En este contexto, los territorios deben entenderse como "construcciones sociales" y como el resultado de un entramado de relaciones multiescalares e interdependientes por los flujos y por las redes de toda naturaleza, definiendo una perspectiva relacional que requiere de instancias de decisión multilocalizadas, exigiendo además recuperar el papel del Estado para avanzar hacia políticas de justicia distributiva entre grupos sociales y territorios (Moncayo, 2008, p. 174-175, en De Mattos, 2010, p. 714).

Los escenarios para el futuro que se plantearon al inicio del siglo XXI reconocieron la exigencia de recuperar a los territorios para contar con una organización sólida con capacidad de articular a las ciudades como parte de los objetivos regionales y nacionales de desarrollo económico y de reducción de la pobreza y la desigualdad.

Para ello, se planteó desde la Comisión Económica para América Latina y el Caribe (CEPAL) la necesidad de desarrollar "...una política fiscal coherente con el desarrollo de los espacios subnacionales, las regulaciones para la sostenibilidad del medio urbano, los arreglos para la cooperación público-privada en la provisión de equipamientos e infraestructura y el desarrollo de mercados de bienes y servicios a nivel local ...[igualmente]... un mejoramiento constante en el nivel de servicios, tanto a la empresa como a la familia, para lograr un aumento en los beneficios y la productividad de la actividad económica” (Jordán, 2003, p. 67-68).

Desde la óptica de la sostenibilidad promovida entonces, estas políticas buscaban equilibrar crecimiento económico con desarrollo social y con una mejora en el manejo del ambiente desde la perspectiva urbana, tratando de alcanzar una mejor habitabilidad y funcionalidad de las ciudades.

Sin embargo, no ha estado claro cómo avanzar en este sentido sin transformar las reglas del modelo de acumulación capitalista que han sido las principales responsables del problema. Calix (2017) aporta una interesante explicación al destacar las rupturas y continuidades entre los periodos históricos recientes del desarrollo capitalista latinoamericano, haciendo notar la presencia en cada uno de ellos de tres elementos comunes:

a) Conciben la modernización como un proceso evolutivo y lineal basado en el crecimiento ilimitado de la economía y, agregaríamos, en la concentración de la riqueza en pocas manos, sin que el mercado asuma responsabilidad alguna en el desarrollo social, trasladando ésta a los gobiernos, no obstante que en buena medida éstos son creados a imagen y semejanza del propio mercado capitalista.

b) Subordinan y niegan el valor intrínseco de la naturaleza en las relaciones entre el ser humano y el ambiente, imponiendo procesos productivos que extraen, casi sin límite y con baja consideración para el ambiente, los recursos naturales en la región.

c) Excluyen saberes que se apartan de la racionalidad occidental hegemónica y por ello, más allá de las diferencias entre países y subregiones, puede afirmarse que América Latina sigue sin modificar a fondo su papel en la división internacional del trabajo.

En síntesis, la crisis que enfrenta la región, agudizada por la pandemia de COVID-19 y por la amenaza que se está cumpliendo del cambio de clima, es una crisis societal del modelo capitalista, su mercado hegemónico y su estructura política.

ACE, 15 (4:3) CC BY-ND 3.0 ES | UPC Barcelona, España $\mid$ La ciudad que quisiéramos después de COVID-19. 10 DOI: http://dx.doi.org/10.5821/ace.15.43.9512 
Por ello, los programas para reducir la pobreza, la desigualdad, el extractivismo y el deterioro ambiental, fundados en las mismas reglas y estructuras del statu quo evidencian la incapacidad de los gobiernos y los mercados de reconocer que son la causa de la crisis que pretenden resolver.

\section{La ciudad resultante: caldo de cultivo para COVID-19}

Los argumentos anteriores permiten reconocer que, desde el inicio del Periodo Neoliberal hasta la segunda década del nuevo siglo, en las ciudades latinoamericanas se han agudizado procesos de urbanización acelerada, desordenada y descapitalizada, y ha predominado la "ciudad del capital", en la que los excesos especulativos y la abdicación de los gobiernos en el ordenamiento urbano han redefinido las ciudades provocando diversas consecuencias, entre las que destacan las siguientes:

En primer lugar, América Latina es la región más urbanizada del planeta y sus metrópolis han transitado a patrones territoriales regionales (ciudad-región, megalópolis...) para los cuales no existen experiencias ni criterios claros de planificación y ordenamiento (Balbo, 2003).

Destaca la tendencia a la pérdida de productividad promedio de las ciudades como resultado de estructuras físicas urbanas cada vez menos funcionales; inflación en los valores inmobiliarios por encima del resto de los mercados; reducción sensible en la movilidad sustentable y en la calidad del transporte, elevando los costos sociales y económicos, y reduciendo la productividad por habitante.

En segundo lugar, la pobreza, la desigualdad social y espacial y la violencia destacan en muchas ciudades latinoamericanas. En el continente americano, Nueva Orleans (0.58) (Bloomberg, 2015), Nueva York (0.51) (Holland, 2014), Filadelfia (0.50) y Cleveland (0.50) son las ciudades con mayor desigualdad en EUA (World Bank, 2019). Muchas metrópolis latinoamericanas están cerca de estos índices: La Paz (0.56), Santiago (0.56), Bogotá (0.53), Buenos Aires (0.51), Asunción (0.50) y Ciudad de México (0.48), mientras que Brasilia (0.68) parece ser la metrópoli más desigual en América Latina (UN-Habitat, 2016).

En mayo de 2020 la CEPAL publicó un reporte especial sobre la pandemia de COVID-19 en el que las proyecciones del crecimiento de la desigualdad y de la pobreza y la extrema pobreza son muy alarmantes: un incremento de 28.7 millones de personas en pobreza y 15.9 millones de personas en extrema pobreza de 2019 a 2020 (CEPAL, 2020) (Tabla 2).

Tabla 2. Proyección de la población en pobreza y extrema pobreza en 2020 en 17 países de América Latina sin considerar los métodos para mitigar el impacto de COVID-19 (porcentajes)

\begin{tabular}{|c|c|c|c|c|c|c|c|c|}
\hline \multirow{3}{*}{ País } & \multicolumn{4}{|c|}{ Pobreza extrema } & \multicolumn{4}{|c|}{ Pobreza } \\
\hline & \multirow{2}{*}{$\begin{array}{l}2019^{a} \\
\text { Nivel }\end{array}$} & \multicolumn{3}{|c|}{$2020^{b}$} & \multirow{2}{*}{$\frac{2019^{a}}{\text { Nivel }}$} & \multicolumn{3}{|c|}{$2020^{b}$} \\
\hline & & $\begin{array}{c}\text { Escenario } \\
\text { Bajo }\end{array}$ & $\begin{array}{c}\text { Escenario } \\
\text { Medio }\end{array}$ & $\begin{array}{c}\text { Escenario } \\
\text { Alto }\end{array}$ & & $\begin{array}{c}\text { Escenario } \\
\text { Bajo }\end{array}$ & $\begin{array}{c}\text { Escenario } \\
\text { Medio }\end{array}$ & $\begin{array}{c}\text { Escenario } \\
\text { Alto }\end{array}$ \\
\hline Argentina $^{c}$ & 3,8 & 5,1 & 5,5 & 6,3 & 26,7 & 32,5 & 33,6 & 35,3 \\
\hline Bolivia & 14,3 & 15,4 & 16,0 & 16,7 & 32,3 & 33,6 & 34,4 & 35,5 \\
\hline Brasil & 5,4 & 6,9 & 7,4 & 7,9 & 19,4 & 23,0 & 24,3 & 25,4 \\
\hline Chile & 1,4 & 2,1 & 2,3 & 2,6 & 9,8 & 11,9 & 12,7 & 13,7 \\
\hline Colombia & 10,3 & 11,3 & 12,0 & 12,7 & 29,0 & 30,4 & 31,5 & 32,5 \\
\hline Costa Rica & 4,0 & 4,7 & 4,9 & 5,3 & 16,0 & 17,7 & 18,4 & 19,1 \\
\hline Ecuador & 7,6 & 9,9 & 10,7 & 11,6 & 25,7 & 30,0 & 30,8 & 31,9 \\
\hline El Salvador & 7,4 & 8,5 & 9,0 & 9,6 & 33,7 & 35,4 & 36,4 & 37,3 \\
\hline Guatemala & 19,8 & 21,2 & 21,4 & 21,8 & 48,6 & 50,3 & 50,5 & 50,9 \\
\hline
\end{tabular}

ACE, 15 (4:3) CC BY-ND 3.0 ES | UPC Barcelona, España | La ciudad que quisiéramos después de COVID-19. 11 DOI: http://dx.doi.org/10.5821/ace.15.43.9512 


\begin{tabular}{|l|c|c|c|c|c|c|c|c|}
\hline Honduras & 18,7 & 19,5 & 19,8 & 20,5 & 54,8 & 56,3 & 57,1 & 57,8 \\
\hline México & 11,1 & 14,9 & 15,9 & 17,1 & 41,9 & 46,7 & 47,8 & 48,9 \\
\hline Nicaragua & 18,0 & 20,7 & 21,3 & 22,2 & 47,1 & 50,6 & 51,6 & 52,7 \\
\hline Panamá & 6,2 & 6,4 & 6,6 & 6,8 & 14,2 & 14,5 & 14,9 & 15,6 \\
\hline Paraguay & 6,2 & 6,3 & 6,5 & 6,9 & 19,4 & 19,8 & 20,3 & 21,1 \\
\hline Perú & 3,7 & 4,6 & 4,8 & 5,1 & 16,5 & 18,5 & 19,1 & 20,1 \\
\hline $\begin{array}{l}\text { República } \\
\text { Dominicana }\end{array}$ & 4,5 & 4,6 & 4,9 & 5,3 & 20,3 & 20,7 & 21,1 & 21,7 \\
\hline $\begin{array}{l}\text { Uruguay } \\
\text { América } \\
\text { Latina d }\end{array}$ & 0,1 & 0,2 & 0,3 & 0,4 & 2,9 & 4,2 & 4,8 & 5,7 \\
\hline
\end{tabular}

Fuente: CEPAL (2020: 2). ${ }^{a}$ Corresponde a áreas urbanas.; ${ }^{b}$ Proyección.; ${ }^{\circ}$ Proyecciones preliminares basadas en el impacto asumido en empleo e ingreso en diferentes sectores productivos. Los tres escenarios fueron calculados sobre la variación del ingreso promedio de los hogares siendo más bajo que la variación del PIB (escenario bajo), igual (escenario medio) y más alto (escenario alto).; ${ }^{d}$ Corresponde a los 17 países de la tabla y a la República Bolivariana de Venezuela.

En América Latina se ubican 20 de las 25 ciudades más violentas del mundo desde la perrpectiva del número de homicios por cada 100 mil habitantes (2016), teniendo los Estados Unidos otras 4 (Figura 6). En América Latina, al igual que en otros lugares, la violencia homicida tiende a hiperconcentrarse espacialmente en las áreas urbanas periféricas de muy bajo ingreso que enfrentan grandes carencias y desventajas.

"Las ciudades, especialmente las que crecen muy rápido, ofrecen oportunidades para las actividades criminales como consecuencia del abandono económico y de la ausencia o insuficiencia de servicios básicos urbanos. La violencia puede también conformarse por la alta densidad de delincuentes actuales y los que podrán serlo, que corresponde particularmente a jóvenes desempleados." (Muggah, 2019, p. 19-21. Traducción del autor)

Figura 6. Las ciudades más violentas en el mundo por el número de homicidios, 2016 (homicidios por cada 100,000 habitantes)

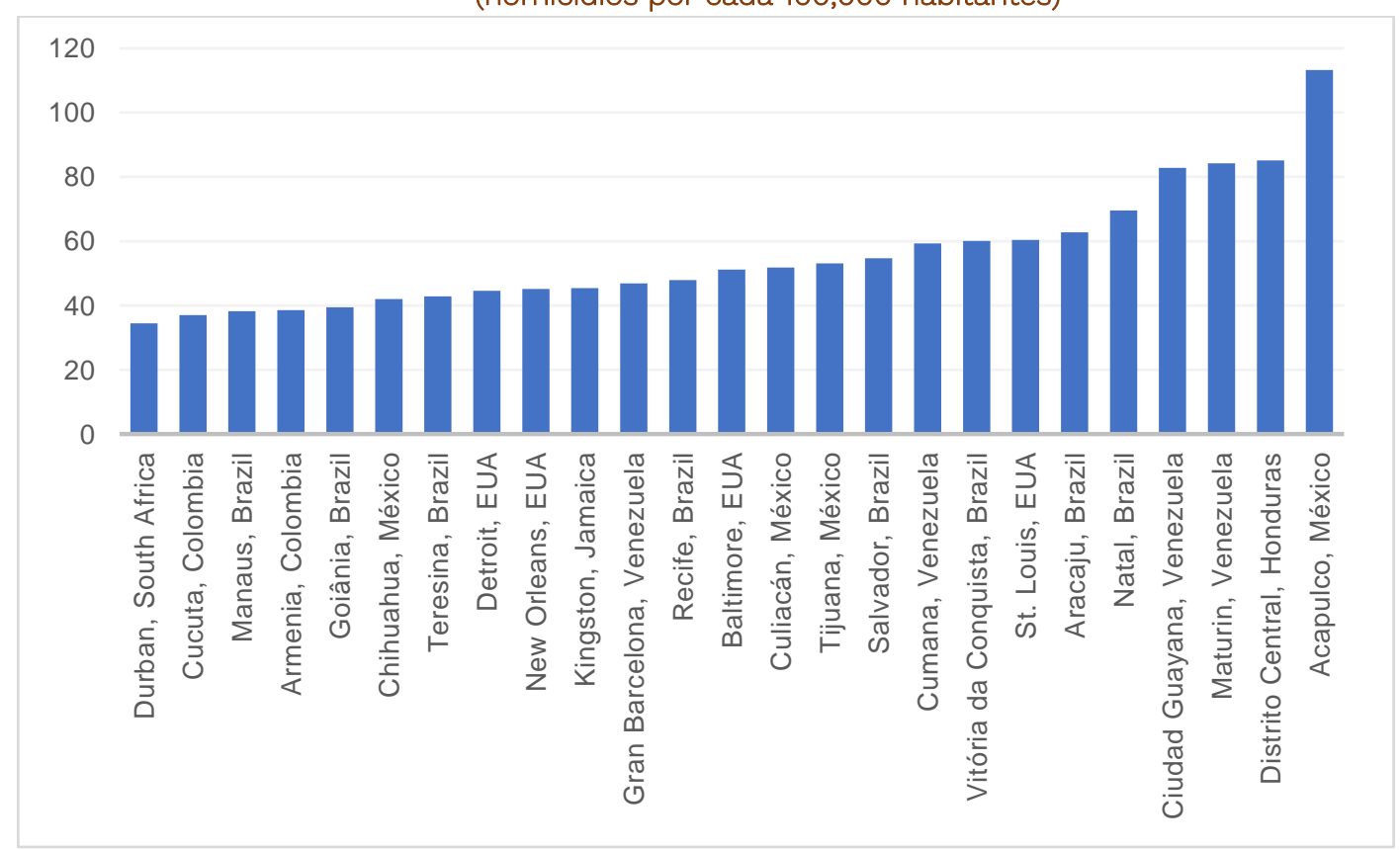

Fuente: Elaboración propia con datos de Business Insider (2017, p. 4).

ACE, 15 (43) CC BY-ND 3.0 ES | UPC Barcelona, España | La ciudad que quisiéramos después de COVID-19. 
La creciente pérdida de las capacidades, recursos, poder y legitimidad de los gobiernos nacionales y locales para orientar, controlar y corregir los procesos de hiperurbanización y sus consecuencias, tiene su origen en el abandono estatal del concepto de "lo público" y "lo comunitario" a favor de lo mercantil, empresarial e individualista. Destaca, entre sus consecuencias, la conversión de la mayor parte de las ciudades latinoamericanas en espacios-mercancía, lo que ha acelerado la desigualdad socioespacial y la insustentabilidad, haciendo de los mercados financiero, constructor e inmobiliario (formal e informal) los verdaderos orientadores del crecimiento urbano.

Un ejemplo claro podría ser Brasil; como menciona De Faria (comunicación personal, junio 05, 2020), la pobreza, la precarización del trabajo, las viviendas sin infraestructura de saneamiento (agua y drenaje) y la ausencia de políticas públicas en el área de la salud, entre tantos otros servicios urbanos fundamentales, son ahora factores que dramatizan la pésima situación urbano-regional de Brasil. En la medida en que el actual gobierno federal simplemente no asume su papel en la planeación nacional y está orientado únicamente por una agenda ultraliberal estructurada por una política financiera, basada en la rigidez fiscal, la privatización y en la reducción de los derechos sociales, muy diferente de una propuesta de planificación y de política económica basada en el desarrollo y la distribución de la riqueza, el COVID-19 ha encontrado condiciones perfectas para diseminarse descontroladamente, como se puede apreciar a diario con sólo dar seguimiento a las noticias de los medios de comunicación.

En tercer lugar, el problema de la vivienda social. Para la mayor parte de la población urbana de bajo ingreso de América Latina, la VIVIENDA ADECUADA representa el mayor y en muchos casos el único componente del patrimonio familiar; además de ofrecer mayor seguridad y oportunidades laborales, la vivienda favorece sobre todo la mejora en la calidad de vida del núcleo familiar (Guevara y Arce, 2016). Sin embargo, la realidad de la vivienda urbana en buena parte de América Latina se caracteriza por la segregación socioespacial.

Si bien existe la segregación socioespacial voluntaria de los grupos de alto ingreso que habitan en las mejores localizaciones dentro y fuera de las ciudades en conjuntos residenciales cerrados con todos los servicios y garantías de seguridad para sus pobladores, en las ciudades de América Latina destaca la segregación socioespacial involuntaria de los grupos sociales de mediano, bajo y muy bajo ingreso.

Los dos primeros son en muchos casos "beneficiarios" de las políticas de vivienda social de los países, mientras que los grupos de muy bajo ingreso habitan en asentamientos precarios e informales y en zonas de riesgo. Los espacios habitacionales de ambos se caracterizan por localizarse en las periferias cada vez más alejadas de los centros urbanos, convirtiéndose desde el inicio de este siglo es una de las consecuencias más graves de la expansión ilimitada de las ciudades latinoamericanas.

La causa de esta segregación involuntaria de millones de personas es que no pueden pagar una vivienda o un pedazo de suelo dentro de la ciudad consolidada que esté bien localizado y con los servicios básicos urbanos; la razón de esto es el dominio de procesos especulativos que mantienen artificialmente altos los precios del suelo favorecidos por los gobiernos y operados por las empresas, los desarrolladores, la banca, los constructores, los propietarios de la tierra y un sinnúmero de otros actores, sean organizaciones sociales o personeros locales. En este sentido, el uso del suelo en las ciudades de la región latinoamericana sigue siendo feudo de los mercados inmobiliarios -formales e informales-, generalmente fuera del control gubernamental y social, con la (casi) única excepción de Cuba.

La Relatora Especial sobre Vivienda de la ONU reconoce que los habitantes de bajo ingreso en asentamientos informales son víctimas de violación de sus derechos humanos. Sin embargo, más allá de ser fundamental atenderlos como víctimas, se debe reconocer que muchas organizaciones

ACE, 15 (4:3) CC BY-ND 3.0 ES | UPC Barcelona, España | La ciudad que quisiéramos después de COVID-19. 13 DOI: http://dx.doi.org/10.5821/ace.15.43.9512 
comunitarias han generado sistemas no gubernamentales de producción social de vivienda, de bienestar social, de seguridad habitacional y de infraestructura básica a través de prácticas marginales de orden económico, político y social, prácticamente sin apoyo del Estado o de los mercados habitacionales, demostrando el valor de la urbanización de base social. Estas organizaciones han asumido en la práctica, la provisión de algunos servicios que son originalmente responsabilidad estatal, a través de una especie de contrato social sobre la informalidad que facilita la estructura de producción de bienestar social no gubernamental en áreas urbanas muy densas en países en desarrollo (Davy and Pellissey, 2013, abstract).

Como afirman expertos latinoamericanos en vivienda de 13 países (Varios autores, 2014), la vivienda social no es sólo un asunto de política pública, sino de garantías de tenencia segura, de respeto a las condiciones de cada país y de cada ciudad cuando se diseñan los grandes conjuntos de viviendas y, sobre todo, del reconocimiento del derecho humano que todos deben satisfacer, frente a la condición de mercancía como única opción, a la que la vivienda ha sido confinada en prácticamente todos los países latinoamericanos.

La falta de cumplimiento del concepto de vivienda adecuada en la mayor parte de las ciudades de la región se ha convertido en una de las causas del agudizamiento de las consecuencias de la pandemia de COVID-19, porque las viviendas y los conjuntos donde las concentran carecen de las condiciones mínimas para enfrentar las directrices gubernamentales relativas a: "quedarse en casa"; "mantener sana distancia con otras personas" y "lavarse las manos constantemente". La magnitud de las viviendas producidas en la región a lo largo del presente siglo y el número de personas que involucra da una idea de la dimensión del problema generado por estas políticas públicas diseñadas y ejecutadas con visiones casi exclusivas de mercado (Figura 7).

Figura 7. Producción de vivienda social en países seleccionados de América Latina y El Caribe, 2010-2015 ${ }^{1}$

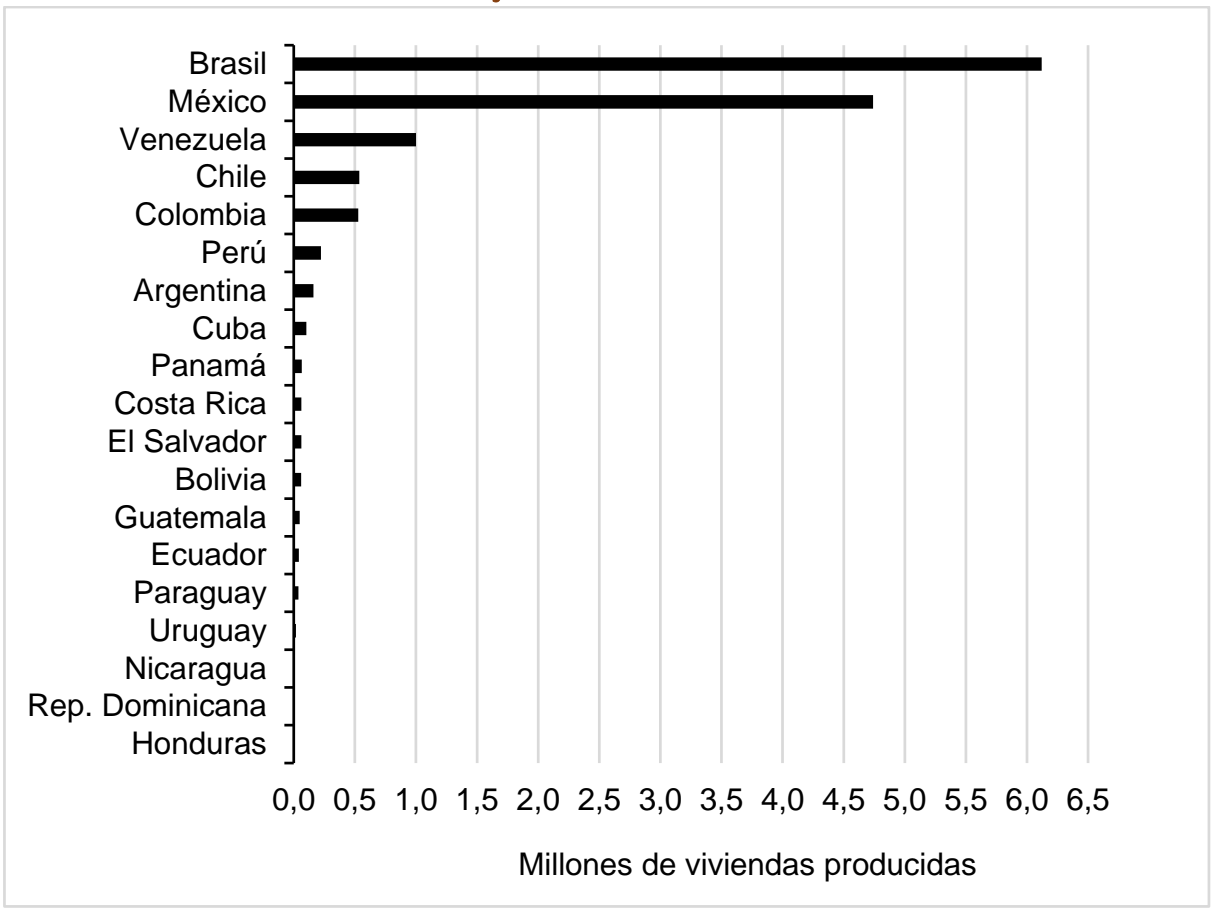

${ }^{1}$ Se presentan datos de aquellos países con información disponible sobre el número de viviendas de interés social producidas con recursos públicos durante el periodo 2010-2015. Los países que no cumplieron tal condición no fueron incluidos. Fuente: Iracheta (2020, p. 73).

ACE, 15 (4:3) CC BY-ND 3.0 ES | UPC Barcelona, España | La ciudad que quisiéramos después de COVID-19. 
En la época más reciente surge la financiarización inmobiliaria, en la que se confunde el sector financiero con fracciones del inmobiliario y constructor, provocando diversas crisis: las derivadas de hipotecas subprime y las que proceden de la sobreproducción de vivienda social y su mala localización en la periferia urbana y sin los equipamientos urbanos que requiere su población, dando pie a movimientos como los "sin techo" y su tránsito a los "con techo", acelerando la creciente especulación con el suelo urbano y urbanizable.

En cuarto lugar, los asentamientos irregulares y precarios. Siguen siendo la (casi) única opción de asentamiento para millones de personas de muy bajo ingreso en las ciudades de América Latina. Entre 1990 y 2010 la población que habita en estos asentamientos en los países en desarrollo pasó de 657 a 827 millones (United Nations, 2010), y se estima que en América Latina concentran del orden de 110 millones de habitantes, lo que representa más de 25\% del total de hogares en la región. Esta magnitud se incrementa por el número de hogares que se encuentran también con tenencia desactualizada y/o en condiciones de informalidad, alcanzando aproximadamente a $70 \%$ de los hogares urbanos (Siclari, 2017).

Una marcada evidencia es que en general, las ciudades latinoamericanas se han caracterizado por la presencia, cada vez más relevante por su magnitud y localización, de asentamientos informales y/o irregulares y/o ilegales, al grado que se considera que su crecimiento desde la década de 1970 ha superado al de la urbanización general, convirtiendo en sinónimos a "urbanización” y "favelización" (Davis, 2013, p. 27, citado por Granero, 2017, p. 74).

Si bien estas magnitudes son diferentes en cada país y ciudad, pareciera haber coincidencia en que más de la mitad de las viviendas de bajo ingreso en las ciudades latinoamericanas han tenido su origen en procesos de ocupación y/o compra irregular y/o informal y/o ilegal de suelo y han sido autoconstruidas, alcanzando en México, por ejemplo, a 6 de cada 10 (CIDOC/SHF, 2011).

El crecimiento de estos asentamientos precarios e informales es una de las manifestaciones de la ruptura del tejido social urbano; se asocia a la crisis de las expectativas sociales sobre el desarrollo y la buena vida urbana y es resultado del incumplimiento sistemático de promesas de los políticos y los gobernantes, así como del engaño persistente de los mercados, fuertemente impulsado por los medios de comunicación, destacando la TV y más recientemente las redes sociales. Se manifiesta en la intensificación de los conflictos y la inconformidad social en las ciudades, materializada en una participación masiva y violenta (mítines, pintas, tomas de edificios, etc.) de grupos sociales que concentran reclamos sobre temas urbanos. Estas manifestaciones rompen buena parte de los arreglos institucionales y ponen en riesgo el Estado de Derecho ante la falta de interlocución con los gobiernos.

En quinto lugar, la degradación del espacio público en las ciudades atenta contra la ciudadanía, porque ésta se construye principalmente en el espacio público -la ciudad es fundamentalmente su espacio público-, y una ciudad más justa y equitativa tiene en el espacio público uno de sus instrumentos fundamentales de integración social.

El problema en muchas ciudades latinoamericanas es que la representación del espacio público se caracteriza por calles, plazas y parques descuidados, obscuros e inseguros, apropiados por comercio informal y ambulante, mostrando la idea de lugares sin pertenencia y por ello, sin capacidad para ofrecer atractivo para la vida urbana, como lo evidencia el hecho que en las mediciones internacionales de calidad de vida urbana, ninguna ciudad latinoamericana aparece dentro de los primeros 50 lugares (Páramo et al., 2018), confirmando la desconsideración generalizada del espacio público urbano en la región.

ACE, 15 (4:3) CC BY-ND 3.0 ES | UPC Barcelona, España | La ciudad que quisiéramos después de COVID-19. 
Se debe entender también que el espacio público en las ciudades latinoamericanas es al mismo tiempo la "arena" en la que se manifiestan los conflictos sociales. Ejemplos recientes son las acciones contestatarias y protestas en los centros de las ciudades en Santiago de Chile, Caracas, Sâo Paulo y Ciudad de México, entre otras muchas ciudades del mundo como Hong Kong y París. A nivel mundial representan un proceso de "participación social" y de apropiación del espacio público, aunque en varios casos ocurre de manera espontánea y violenta, mostrando las limitadas capacidades y voluntad política de los gobiernos para resolver los problemas urbanos antes que las protestas aparezcan.

En sexto lugar, la calidad y cobertura de los sistemas de transporte en las ciudades latinoamericanas son determinantes en la movilidad, la conectividad y la accesibilidad cotidiana de la población a los servicios sociales fundamentales, destacando los relativos a la prevención y atención de la salud.

Más de la mitad de los viajes diarios en las grandes ciudades de América Latina se realizan en transporte público, rebasando en algunas el 70\% -Ciudad de México, Lima, Montevideo, Panamá, Quito y San Salvador, entre otras-. Como promedio, se realizaron 0.82 viajes/persona/día (v/p/d) en transporte público frente a $0.55 \mathrm{v} / \mathrm{p} / \mathrm{d}$ en automóvil individual y $0.50 \mathrm{v} / \mathrm{p} / \mathrm{d}$ a pie y en bicicleta (2015). Sin embargo, visto como tendencia, entre 2007 y 2015 la tasa promedio anual de crecimiento del transporte público fue negativa (-1.67\%), mientras que la del automóvil individual fue positiva (0.37\%), siendo destacable también que la tasa de crecimiento anual de los $\mathrm{v} / \mathrm{p} / \mathrm{d}$ a pie o en bicicleta sea negativa (-0.34\%) (Iracheta, 2020, p. 89).

Esto es consecuencia de varios procesos concatenados: en primer lugar, salvo muy limitadas excepciones, la calidad promedio de los transportes públicos en las ciudades de América Latina es baja, afectando de manera directa a la población de menor ingreso. En segundo lugar, la mayoría de los espacios habitacionales para grupos sociales de mediano y bajo ingresos, incluyendo los conjuntos de vivienda social promovidos por el Estado (Iracheta, 2015), se integran sólo parcialmente a la trama urbana existente, constituyéndose en islas dentro de la ciudad o en su periferia, en muchos casos lejana, interrumpiendo la conectividad con el resto del área urbana y con las áreas residenciales aledañas, por lo que sus habitantes enfrentan serias limitaciones para acceder a servicios de salud y otros servicios públicos (Jirón et al., 2004). Finalmente, desde los mercados y desde los Estados se ha impulsado de manera muy enfática el uso de automóvil individual, concentrándose buena parte de las inversiones públicas en las infraestructuras para éstos y no para el transporte público o las opciones no motorizadas.

Como consecuencia, un denominador común en buena parte de las ciudades latinoamericanas es el tráfico vehicular excesivo y frecuentemente congestionado con su correspondiente impacto en la calidad del aire, en el creciente consumo de energías fósiles y en el deterioro de la salud de la población, facilitando las condiciones para la agudización de enfermedades respiratorias como COVID-19 (Iracheta, 2020, p. 89-90).

Finalmente, en séptimo lugar, el Reporte Global de los Asentamientos Humanos 2011 de ONU-Hábitat indica que entre 30.5 y 40.8\% del total de los GEI son generados en las ciudades (UN-Habitat, 2011) que apenas ocupan del orden de $2 \%$ de la superficie del planeta, proporción que se eleva considerablemente hasta $70 \%$ si se consideran las emisiones indirectas a su funcionamiento; por ello, las ciudades tienen una gran responsabilidad en el cambio climático. En la región se aprecia un agudizamiento de la crisis ambiental urbana: atmosférica, hídrica, del suelo, por ruido, visual, etcétera, afectando de manera creciente al ambiente y a su población, convirtiéndose en caldo de cultivo de enfermedades como COVID-19.

Como establece MINURVI: "Varias de las causas de deterioro del medio ambiente en general se originan en las áreas urbanas como consecuencia de la polución del aire ocasionada por las industrias y el parque automotriz, o por la producción descontrolada de residuos y la contaminación del agua

ACE, 15 (4:3) CC BY-ND 3.0 ES | UPC Barcelona, España | La ciudad que quisiéramos después de COVID-19. 16 DOI: http://dx.doi.org/10.5821/ace.15.43.9512 
[...] Si bien el cambio climático es un proceso que afecta a todas las zonas del planeta por igual, adquiere mayor relevancia en las ciudades debido a los impactos que pueden provocar en la población los desastres producidos por eventos meteorológicos extremos" (2016, p. 28). En 2012 se realizó un estudio en 16 países de la región latinoamericana en el que se registró que entre 1990 y 2011 ocurrió un total aproximado de 42 mil víctimas fatales, 1 millón de viviendas destruidas y cerca de 6 millones afectadas (McKinsey Global Institute, 2013, p. 28) como consecuencia de fenómenos ambientales que en buena parte son provocados por la acción humana.

A manera de síntesis, los siete grandes temas expuestos ofrecen una idea de las ciudades que han resultado del proceso histórico de desarrollo de América Latina, especialmente en el último periodo de urbanización neoliberal.

\section{Para no concluir: otra ciudad es posible}

El valor social e intangible de la ciudad a través de sus instituciones y organizaciones es el factor central para enfrentar una crisis como la de COVID-19 y para controlar su diseminación. Este valor radica en la capacidad de la sociedad y del Estado para proveer bienestar. Como ha indicado la CEPAL (2020), la pandemia ha expuesto los problemas estructurales del modelo económico y las fallas de los sistemas de protección social y los esquemas de atención a la salud en los países latinoamericanos, lo que se ha vuelto muy costoso para todos. Por ello, debemos movernos a crear un nuevo Estado de Bienestar basado en un nuevo modelo social orientado a reducir sensiblemente la pobreza y la desigualdad en la distribución de la riqueza; que garantice en las ciudades los principios y acciones del Derecho a la Ciudad y a la Vivienda Adecuada y que tome en cuenta las materias relacionadas de orden fiscal, social y de producción. Los gobiernos de las ciudades y los actores sociales necesitan actuar a la vez que responder ¿cómo las ciudades pueden ser al tiempo actores y los lugares para esta transformación?

Un principio que debiera guiar el compromiso y la actuación de todos es que los cambios exigen respuestas que vayan más allá de lo ordinario, porque las transiciones post-COVID-19 deben partir por reconocer que esta pandemia se inserta en la crisis sistémica global que tiene al cambio climático y a la desigualdad como sus temas más evidentes y más graves.

Por ello, para enfrentar la desigualdad social y espacial, y para “...mantenernos dentro de los límites planetarios identificados por el Stockholm Resilience Center en 2009, son ineludibles la salida del capitalismo fósil, el cambio de nuestros sistemas energéticos a fuentes renovables y a una reducción significativa del uso de energía, la salida o modernización de las grandes industrias tradicionales, la recuperación de los ecosistemas degradados por el cambio de uso del suelo, la transformación de las ciudades con énfasis en la ampliación y mejora del transporte público, una nueva política de vivienda que enfrente la especulación financiera y un nuevo ordenamiento territorial que priorice la protección de lo social, lo ambiental y lo público" (Friedrich Ebert Stiftung, 2019, p. 10).

Desde la perspectiva de las ciudades, es necesario gestionar una "Matriz Territorial" diferente, que conceptualmente... "implica construir otras políticas, otros consensos y nuevos procesos de gobernanza y participación social como instrumentos para promover y para luchar por una transformación de las ciudades y sus entornos rurales y regionales de América Latina a favor de un desarrollo productivo, incluyente, ordenado y sustentable, desde una perspectiva social-ecológica y con un enfoque políticamente PROGRESISTA" (Iracheta, 2020, p. 9-10), que reconozca a las ciudades como los espacios más adecuados para el desarrollo, ya que concentran el empleo de calidad, el más productivo y creativo (Florida, 2005), y concentran los impactos positivos en la productividad y en la calidad de vida. Que reconozca también que en ellas se deben priorizar otras economías que

ACE, 15 (43) CC BY-ND 3.0 ES | UPC Barcelona, España | La ciudad que quisiéramos después de COVID-19. 17 DOI: http://dx.doi.org/10.5821/ace.15.43.9512 
son posibles más allá de sólo el mercado capitalista neoliberal, como la economía social y solidaria o las economías de los cuidados.

Así como las áreas urbanas son responsables de la emisión de GEI, se reconoce también que ofrecen la mejor oportunidad para mitigar el cambio climático, adaptando y corrigiendo los patrones de urbanización y de producción-circulación y consumo, al concentrar el poder de decisión política, económica y social y el conocimiento sobre estos problemas y sus soluciones, destacando tres temas centrales: los usos del suelo, los modos de transporte y el consumo de energía fósil asociado a la producción y a la urbanización (UN-Habitat, 2011).

Una matriz territorial diferente debe poner por delante el Derecho a la Ciudad, en el sentido de que cada ciudad sea un proyecto social-ecológico compartido y sostenido socialmente y no un destino fatal; es en este contexto que se debe replantear la política pública de salud y desarrollar sistemas comunitarios de prevención y atención sanitaria. Igualmente, debemos retomar la lucha por una vivienda adecuada y por la recuperación de los espacios públicos; por el desarrollo de transporte público y no motorizado sostenibles; por la recuperación de las plusvalías inmobiliarias a favor de la comunidad urbana y por llevar las TIC a los espacios populares. Todo ello emanado de una gran estrategia de recuperación de los principios y políticas de bienestar social en cada país y ciudad de América Latina.

Una matriz territorial diferente debe también partir por reconocer el "derecho de la naturaleza" y asumir al CAMBIO CLIMÁTICO como un reto urbano, desarrollando otras políticas de uso del suelo, de consumo de energía y de movilidad, y replanteando la estructura espacial de nuestras ciudades poniendo a debate la construcción de nuevas políticas que le den sentido a conceptos como la densidad, la compactación y consolidación urbanas, la mezcla de usos y funciones urbanas, la vuelta al barrio como célula básica de la ciudad y la determinación de centralidades a diferentes escalas espaciales, entre otros conceptos y estrategias que permitan transformar nuestras ciudades para que sean más equitativas, sustentables y resilientes ante la incertidumbre y las nuevas amenazas y pandemias.

La condición fundamental de una matriz territorial diferente es que las ciudades sean bien gobernadas (OECD, 2015), lo que implica una democracia funcional, rendición de cuentas de los recursos públicos, políticas redistributivas de los beneficios de la urbanización y un compromiso con el ambiente urbano y de su región. Es decir, reconocer que el Estado sí importa y por ello, se debe luchar por un Estado fuerte para tener mercados fuertes que sean social y ambientalmente responsables. Implica también repensar y asumir otras formas de planificación y gobierno urbano, y en este sentido, transitar hacia la gobernanza territorial puede ser un camino a recorrer por las ciudades latinoamericanas, reconociendo los avances logrados en algunas de ellas y centrándose en algunas estrategias:

- Participación corresponsable en las decisiones que afectan a la comunidad urbana, destacando el papel de la mujer en los barrios. Debe incluir la valorización de las solidaridades de clase, de género, territoriales, que en muchos asentamientos y barrios urbanos se han ampliado y visibilizado.

- Recuperar la planificación urbana participativa, integrada y de largo plazo, poniendo por delante el derecho de la comunidad a una ciudad equitativa, ordenada y sustentable y el derecho de la naturaleza y de los territorios, enfrentando con toda las fuerzas sociales y gubernamentales el extractivismo de los recursos naturales y la "carbonización" de las ciudades, y reforzando la cooperación entre ciudades de la región, porque existen buenas prácticas replicables que en general no se difunden.

ACE, 15 (13) CC BY-ND 3.0 ES | UPC Barcelona, España La ciudad que quisiéramos después de COVID-19. 
- $\quad$ Promover el desarrollo de nuevas estructuras institucionales democráticas y participativas (consejos deliberativos y vinculantes, Institutos de planeación participativa, observatorios urbanos).

- Comprometer la aplicación de las agendas internacionales progresistas en las ciudades orientadas a reducir la desigualdad y la pobreza, elevar la productividad de las ciudades, promover el ordenamiento territorial y la sustentabilidad del ambiente.

Estas ideas tienen sentido cuando observamos cambios que "naturalmente" van ocurriendo, sin que necesariamente hayan sido planificados, pero que evidencian nuevos senderos para una transformación social-ecológica de las ciudades latinoamericanas.

El reino del automóvil parece haber llegado a límites que lo ponen en tela de juicio como el instrumento privilegiado de movilidad urbana, por la congestión del tránsito y porque ha llegado el final de la era del petróleo. El surgimiento de nuevas políticas de movilidad y transporte público (Curitiba, Brasil; Bogotá, Colombia; Ciudad de México, entre otras) y nuevas tecnologías automotrices que reducen la contaminación ambiental (vehículos eléctricos, híbridos, de hidrógeno) ofrecen alternativas a la crisis de movilidad de las grandes ciudades.

Conforme crece el aislamiento físico y el distanciamiento social, se aceleran las relaciones virtuales estimuladas por la revolución de las tecnologías de telecomunicación, generando efectos sicológicos y sociales nuevos por su persistencia cotidiana y porque se perciben como la única opción de mantenerse como miembros activos de una comunidad. La explosión de las redes sociales y las TIC como parte de esta revolución está abriendo también el espacio para nuevas estrategias orientadas a la transformación de las ciudades en "prósperas e inteligentes".

El teletrabajo experimentado durante la crisis de COVID-19 ha evidenciado sus posibilidades, pero también sus retos. Su puesta en valor dependerá del respeto a las garantías laborales y del apoyo de las instituciones y empresas a los trabajadores para que sus viviendas y su infraestructura de telecomunicación sean las adecuadas; algo similar ocurrirá probablemente con la educación que se orienta hacia modelos mixtos o híbridos de formación presencial y en línea, y con el abasto, comercio y servicios a distancia que seguramente seguirán una tendencia ascendente en buena parte de las ciudades de la región. Conforme estas tendencias se asienten, la movilidad urbana tendrá cambios relevantes que podrán ser muy positivos si las políticas públicas integran los usos del suelo con las estrategias de transporte.

El teletrabajo, la teleeducación, el telecomercio y el teleconsumo y otras actividades como el teleentretenimiento ofrecen la posibilidad de reducir las necesidades de transporte para muchas personas, reduciendo el número de viajes/persona/día, con sus impactos en la reducción del consumo energético y en la contaminación; sin embargo, es fundamental replantear la política y la normatividad de las viviendas y del hábitat urbano, reconociendo que se abre la oportunidad de regresar a la vida de barrio si en cada uno se cuenta con los equipamientos sociales y los espacios públicos que cada comunidad urbana requiere.

La decisión de repensar la vivienda debe iniciar por su tamaño porque es necesario reconsiderar la superficie del espacio vital individual a fin de permitir privacidad no sólo para descansar, compartir, trabajar, leer y escuchar, sino porque el aislamiento de un enfermo en las viviendas sociales promedio que se han producido en la región al amparo de programas nacionales se vuelve muy difícil de lograr. También debe considerarse su ubicación y distancia a los centros urbanos porque a mayor distancia los costos que pagan los ciudadanos en tiempo y en su ingreso son también crecientes.

ACE, 15 (4:3) CC BY-ND 3.0 ES | UPC Barcelona, España | La ciudad que quisiéramos después de COVID-19. 19 DOI: http://dx.doi.org/10.5821/ace.15.43.9512 
Al tiempo que repensamos la vivienda debemos hacer lo propio en relación con la movilidad. Además de ser los transportes una de las causas directas de la emisión de GEl, después de COVID-19 será muy difícil regresar a los hábitos de transporte anteriores, especialmente en los sistemas públicos siempre congestionados que provocan grandes aglomeraciones y cercanía excesiva entre personas (metro, tren, autobús, taxi colectivo), ofreciendo la posibilidad de revalorar el uso de modos no motorizados como la bicicleta y especialmente caminar, si en paralelo ocurre la regeneración del hábitat local. Sin embargo, es necesario valorar el riesgo de regresar al automóvil individual en sectores de la sociedad urbana que habían sido ganados por transportes públicos. La planificación de la movilidad urbana debe considerar, además de la infraestructura y los medios de transporte, los aspectos económicos, socioculturales y demográficos de la población, porque en las ciudades de la región la accesibilidad de las personas a las funciones urbanas y a los espacios públicos es baja y afecta principalmente a la mayoría pobre de los ciudadanos, convirtiéndose estas limitaciones en causas de expulsión y segregación social y espacial.

Ambos, la vivienda y la movilidad nos exigen repensar la ciudad, sus patrones espaciales y sus densidades a fin de recuperar la intensidad de las relaciones sociales en los espacios públicos. Si bien la densidad nos permite acceder de manera directa y cercana a los equipamientos sociales, la intensidad y concentración de funciones urbanas públicas espacialmente monofuncionales presentan riesgos como pudiera ser el hacinamiento; estos riesgos deben reducirse a través de múltiples centralidades de diferente escala (metropolitana, municipal, barrial), teniendo como eje la mezcla de usos y de funciones urbanas que permitan tener a no más de 15 minutos caminando los servicios directos a la vivienda (educación básica, salud, abasto y otros).

Estas nuevas políticas urbanas que enfaticen lo local deben ofrecer las condiciones y los incentivos necesarios para su realización, de manera que representen una alternativa real contra la suburbia, dispersa y lejana de las centralidades urbanas, que exige largos trayectos, altos costos de transporte y tiempo para los ciudadanos, mayor consumo de energía y crecientes costos para el mantenimiento y expansión de las infraestructuras a cargo de los gobiernos locales.

La pandemia de COVID-19 ha evidenciado que la humanidad está enfrentando una encrucijada histórica y única. La crisis sanitaria está marcada por el cambio climático, la debilidad de las economías y la desigualdad social.

En los pronunciamientos reiterados por organizaciones multilaterales como la CEPAL en la región latinoamericana, se hacen llamados a la transformación del modelo económico, al reinicio del capitalismo, a dejar atrás el crecimiento económico porque sí y orientar las políticas y las acciones sociales a la TRANSFORMACIÓN de todo lo que concierne a la sociedad, iniciando por el mercado, a fin de que sea más justo para todos.

En un mundo hiperurbanizado es fundamental emprender la transformación de las ciudades para que sean justas y funcionen para todos, regenerando los modelos espaciales y las infraestructuras para que no degraden el ambiente y usando la Cuarta Revolución Industrial para crear un mundo que sea más verde y más limpio para favorecer a la humanidad y al ambiente.

La pandemia de COVID-19 ha demostrado la capacidad de los gobiernos para enfrentar una emergencia y prácticamente detener el flujo de la economía y de las relaciones sociales en unos cuantos días en todo el planeta.

¿Es posible imaginar que esta misma energía y capacidad de decisión alineada a nivel global se aplique para enfrentar las amenazas más graves que son el cambio de clima y la hiperconcentración de la riqueza? ¿Es posible poner en valor las perspectivas que ofrecen las ciudades para transformarse después de experimentar la crisis de COVID-19?

ACE, 15 (4:3) CC BY-ND 3.0 ES | UPC Barcelona, España | La ciudad que quisiéramos después de COVID-19. 20 DOI: http://dx.doi.org/10.5821/ace.15.43.9512 
Conflicto de intereses: El autor declara que no hay conflicto de intereses.

\section{Bibliografía}

Balbo, M. (2003). La nueva gestión urbana. En Ricardo Jordán y Daniela Simeoni (comps.). Gestión urbana para el desarrollo sostenible en América Latina y el Caribe (pp. 71-92). Santiago de Chile, Chile: CEPAL.

Bloomberg (2015). The 10 Most Unequal Cities in America. Recuperado de https://www.bloomberg.com/news/articles/2015-11-10/the-10-most-unequal-big-cities-in-america

Business Insider (2017). The 50 Most Violent Cities in the World. Recuperado de https://www.businessinsider.com/most-violent-cities-in-the-world-2017-4.

Calix, A. (2017). El desafío de la transformación social-ecológica en América Latina. Nueva Sociedad, abril 2017. Recuperado de http://nuso.org/articulo/el-desafio-de-la-transformacion-social-yecologica-en-america-latina/

CEPAL, Comisión Económica para América Latina y el Caribe (2020). Datos del Banco de Datos de Encuestas de Hogares (BADEHOG) [Base de datos]. Recuperado de https://repositorio.cepal.org/bitstream/handle/11362/45527/5/S2000325_es.pdf

CIDOC/SHF, Centro de Investigación y Documentación de la Casa/Sociedad Hipotecaria Federal (2011). Estado actual de la vivienda en México. CDMX, México: CIDOC/SHF.

Davis, M. (2013). Planeta Favela. São Paulo, Brasil: Boitempo.

Davy, B. \& and Pellissey, S. (2013). The Citizenship Promise (Un)fulfilled: The Right to Housing in Informal Settings. International Journal of Social Welfare, 22(S1), S68-S84. DOI: https://doi.org/10.1111/ijsw.12033

De Mattos, C. (2010). La cuestión regional en América Latina antes y después del seminario sobre la cuestión regional. En J.L. Coraggio et al. (Alfonso Iracheta, coord.) (2010). La cuestión regional en América Latina, 2a ed. (pp. 689-717). Zinacantepec, México: El Colegio Mexiquense-IIE-UNAM.

Dussel, E. (Autor) (11 de junio, 2020). 2020: La Pandemia con Enrique Dussel. El virus y el problema ecológico [Programa de radio]. Ciudad de México, México: Aristegui Noticias.

Florida, R. (2005). Cities and the Creative Class. New York, USA: Routledge.

Friedrich Ebert Stiftung (2019). Esto no da para más-Hacia la transformación social-ecológica en América Latina (sinopsis). Ciudad de México: Fundación Friedrich Ebert Stiftung (proyecto regional: Transformación social-ecológica).

Granero, R.G. (2017). Territorios de la desigualdad; política urbana y justicia espacial. Buenos Aires, Argentina: Surbanistas.

Guevara, P. y Arce, R. (2016). Estado de la vivienda en Centroamérica. Recuperado de http://x.incae.edu/ES/clacds/publicaciones/pdf/Estado_de_la_Vivienda_en_CA.pdf

ACE, 15 (43) CC BY-ND 3.0 ES | UPC Barcelona, España | La ciudad que quisiéramos después de COVID-19. 21 DOI: http://dx.doi.org/10.5821/ace.15.43.9512 
Harvey, D. (1989). From Manageliarism to Entrepeneurialism: The Transformation in Urban Governance in Late Capitalism. Geographiska Annaler, Series B, Human Geography, 7(1), 3-17. DOI: https://doi.org/10.1080/04353684.1989.11879583

Holland, J. (2014). Tale of Two Cities: New York Has Become the Capital of Inequality. Recuperado de https://billmoyers.com/2014/09/18/tale-of-two-cities-new-york-has-become-the-capitol-of-inequality/

Iracheta, A. (2015). Índice de deterioro habitacional (INDH). Reporte general del diagnóstico de 36 conjuntos habitacionales con altos niveles de vivienda abandonada en México. CDMX, México: Infonavit (elaborado por Centro Eure).

Iracheta, A. (2020). Otra ciudad es posible: los retos del desarrollo urbano en América Latina (título preliminar), Proyecto Regional: Transformación Social-Ecológica en América Latina (TSE). Fundación Friedrich Ebert Stiftung (FES). Ciudad de México, México (libro en prensa).

Jirón Martínez, P.; Toro Blanco, A.; Caquimbo S.; Goldsack, L. \& Martínez Muñiz, L. (2004). Bienestar habitacional: guía de diseño para un hábitat residencial sustentable. Recuperado de https://doi.org/10.34720/s0k1-2823

John Hopkins University (2020). Coronavirus Resource Center. Recuperado de https://coronavirus.jhu.edu/data/mortality

Jordán, R. (2003). Ciudad y desarrollo en América Latina y el Caribe. En Ricardo Jordán y Daniela Simeoni (comps.). Gestión urbana para el desarrollo sostenible en América Latina y el Caribe (pp. 4370), Santiago de Chile, Chile: CEPAL.

Lingzhi Li, M. (2020). Overview of DELPHI Model, COVID Analytics, MIT. Recuperado de https://covidanalytics.io/projections

McKinsey Global Institute (2013). Impacto de los desastres en América Latina y el Caribe, 1990-2011. Recuperado de https://reliefweb.int/sites/reliefweb.int/files/resources/Impacto de los desastres en Las_Americas.pdf

MINURVI (2016). América Latina y el Caribe. Desafíos, dilemas y compromisos de una agenda urbana común. Foro de Ministros y Autoridades Máximas de la Vivienda y el Urbanismo de América Latina y el Caribe. Recuperado de https://repositorio.cepal.org/bitstream/handle/11362/40656/1/S1600986 es.pdf

MIT. (2020). Modelo DELPHI Epidemiological Case Predictions, COVID Analytics. Recuperado de https://covidanalytics.io/projections

Moncayo, E. (2008). Repensando el desarrollo regional. Contribuciones globales para una estrategia latinoamericana. Revista EURE, 34(103), 169-176. DOI: http://dx.doi.org/10.4067/S0250$\underline{71612008000300009}$

Muggah, R. (2019). Foreword. In Jennifer, Erin, Salahub et al. (eds.). Reducing Urban Violence in the Global South. Towards Safe and Inclusive Cities (pp. XIX-XXI) New York, USA: Routledge Studies in Cities and Development.

OECD, Organización para la Cooperación y el Desarrollo Económico (2015). Governing the City. Paris, Francia: OECD Publishing.

ACE, 15 (4:3) CC BY-ND 3.0 ES | UPC Barcelona, España | La ciudad que quisiéramos después de COVID-19. 22 DOI: http://dx.doi.org/10.5821/ace.15.43.9512 
OMS, Organización Mundial de la Salud (2020). Who COVID-19 Global Data. Recuperado de https://covid19.who.int/

Páramo, P.; Burbano, A.; Jiménez Domínguez, B.; Barrios, V.; Pasquali, C.; Vivas, F.; Moros, O.; Alzate, M.; Jaramillo Fayad, J. \& Moyano, E. (2018). La habitabilidad del espacio público en las ciudades de América Latina. Avances en Psicología Latinoamericana, 36(2), 345-362. DOI: http://dx.doi,org/10.12804/revistas.urosario.edu.co/apl/a.4874

Siclari, P. (2017). Desafíos urbanos latinoamericanos y caribeños de cara a los objetivos de desarrollo sustentable y a la nueva agenda urbana. Revista INVI, 32(89), 199-211. Recuperado de https://revistas.uchile.cl/index.php/INVI/article/view/47770/57408

Sugranyes, A.; Morales, R. y Aravena, S. (2014). Chile: Buscando alternativas colectivas en un escenario neoliberal. En Varios autores. La vivienda, entre el derecho y la mercancía: las formas de propiedad en América Latina (pp. 25-35). Montevideo, Uruguay: TRILCE y Centro Cooperativo Sueco We Effect.

UN-Habitat (2011). Cities and Climate Change Global Report on Human Settlements 2011. London, England: Earthscan.

UN-Habitat (2016) World Cities Report 2016, Urbanization and Development, Emerging Futures. Key Findings and Messages. Nairobi, Kenya: UN-Habitat. Recuperado de https://unhabitat.org/world-citiesreport

United Nations (2010). State of the World's Cities, 2010-2011, Overview and Key Findings. Nairoby, Kenya: UN-Habitat. Recuperado de https://sustainabledevelopment.un.org/index.php?page=view\&type=400\& $\underline{\mathrm{nr}=1114 \& \operatorname{menu}=35}$

Varios autores (2014). La vivienda, entre el derecho y la mercancía; las formas de propiedad en América Latina. Montevideo, Uruguay: TRILCE-Centro Cooperativo Sueco.

World Bank (2019). Development Indicators. Recuperado de http://datatopics.worldbank.org/worlddevelopment-indicators/

ACE, 15 (43) CC BY-ND 3.0 ES | UPC Barcelona, España | La ciudad que quisiéramos después de COVID-19.

DOI: http://dx.doi.org/10.5821/ace.15.43.9512 